\title{
Aprendizagem Baseada em Problemas no Ensino de Química Analítica Qualitativa
}

\section{Problem Based Learning in Qualitative Analytical Chemistry Classes}

\author{
Angela Cristina Raimondi ${ }^{1}$ \\ (angela.raimondi@gmail.com) \\ Pontifícia Universidade Católica - PUCPR, Professora Adjunta do Eixo de Química - \\ Escola Politécnica - Curitiba, Paraná.
}

\author{
Eliane Siqueira Razzoto ${ }^{2}$ \\ (eliane.razzoto@gmail.com)
}

Pontifícia Universidade Católica - PUCPR, Professora Assistente do Eixo de Química Escola Politécnica - Curitiba, Paraná.

\section{Resumo:}

Estudantes interessados por uma formação que atenda a demandas exigentes, como a capacidade de resolver problemas, têm procurado cursos de formação superior cujas grades curriculares ofereçam potencial para o desenvolvimento de habilidades e competências de alto nível. O presente trabalho traz os resultados e reflexões sobre a articulação entre metodologia ativa e aprendizagem significativa, direcionada a estudantes do curso de Engenharia Química. Aplicou-se uma atividade pautada na Aprendizagem Baseada em Problemas, que teve como situação-problema a investigação de uma amostra de água contaminada, a qual simulava um efluente de rejeito de uma mineradora. Baseado na descrição do cenário e nas informações preliminares sobre a amostra, os alunos desenvolveram um experimento, em equipes, como modo de responder as questões do estudo. Ao final do trabalho, foram apresentados os resultados de cada grupo, em formato de relatório escrito e de um vídeo da parte experimental. Concluiu-se que a atividade proporcionou uma situação de aprendizagem bastante efetiva para os estudantes. Atribuiu-se o maior envolvimento observado ao longo do acompanhamento deste trabalho ao desenvolvimento de habilidades cognitivas e sociais, oriundo do estímulo de um grupo a lançar mão do método científico para resolver um problema que simula um contexto real.

Palavras-chave: ABP; metodologias ativas; aprendizagem significativa.

\section{Resumo traduzido:}

Students interested in training that meets hard demands, such as problem-solving skills, have sought higher education courses whose curricula offer potential for the development of high-level skills and competences. This paper presents the results and reflections on the articulation between active methodology and meaningful learning, directed to students of Chemical Engineering. An activity based on the methodology of Problem-Based Learning (PBL), which had the problem of investigating a sample of contaminated water, was proposed, simulating a waste effluent from a mining company. Based on the description of the scenario and the preliminary information about the 
sample received, the students developed an experiment, in teams, to answer the questions of the study. At the end, results obtained in each group were presented, as a written report and a video of the experimental work. It was concluded that the activity provided a very effective learning situation for the students. The greatest involvement observed during the follow-up of this work was attributed to the development of cognitive and social skills, derived from the stimulus of a group to use the scientific method to solve a problem that simulates a real context.

Palavras-chave traduzidas: PBL; active methodologies; meaningful learning.

\section{INTRODUÇÃO}

No Brasil, mesmo com as melhorias obtidas no sistema de educação, grande parte das instituições de ensino estão atreladas a metodologias predominantemente tradicionais, onde todo conhecimento está centrado no professor, cabendo a ele atingir o estudante que, por sua vez, aceita as informações de forma passiva e, muitas vezes, desinteressada.

Porém essa estratégia de ensino centrada no professor tende a aniquilar o poder de ação dos alunos, tornando-os meros ouvintes e espectadores do processo. Isto é, existe apenas uma transmissão de ideias, organizada dentro de uma linha única de raciocínio, em que o foco principal é fixar conteúdos (ROSA; SILVA; GALVAN, 2015).

Nesse cenário, o uso de metodologias que busquem alternativas para tirar o foco do docente e proporcionando maior autonomia nos discentes tem despertado bastante interesse no meio acadêmico. Esta abordagem tem grande potencial motivador, para promover o desenvolvimento de competências essenciais para a formação profissional e de cidadãos críticos para a sociedade.

Dessa forma, a aprendizagem baseada em problemas (ABP), originada da expressão em inglês Problem Based Learning (PBL), busca desenvolver uma habilidade que, na atualidade, não é comumente trabalhada em sala de aula: a de aprender a aprender, na qual a essência da abordagem sai do conceito de fórmulas prontas e da realização de tarefas lineares. Ao invés de um enfoque em que o professor ensina o que fazer, como fazer e o que estudar, ou seja, atividades em que o raciocínio e a análise crítica não estão presentes, promovendo uma percepção deformada e empobrecida do processo (GIL PÉREZ et al., 1999), toma lugar uma metodologia de ensino investigativo, baseado no tripé: conceito, atitude e aprendizagem (POZO, 2002).

A Figura 1, adaptada de Hmelo-Silver por Lopes et al. (2011, p. 1276), ilustra o ciclo de aprendizagem na metodologia ABP. Conforme pode ser observado, o processo 
deve ser realimentado sempre que houver necessidade e em qualquer etapa, consistindo basicamente em duas fases: apresentação do problema e estratégia para resolvê-lo.

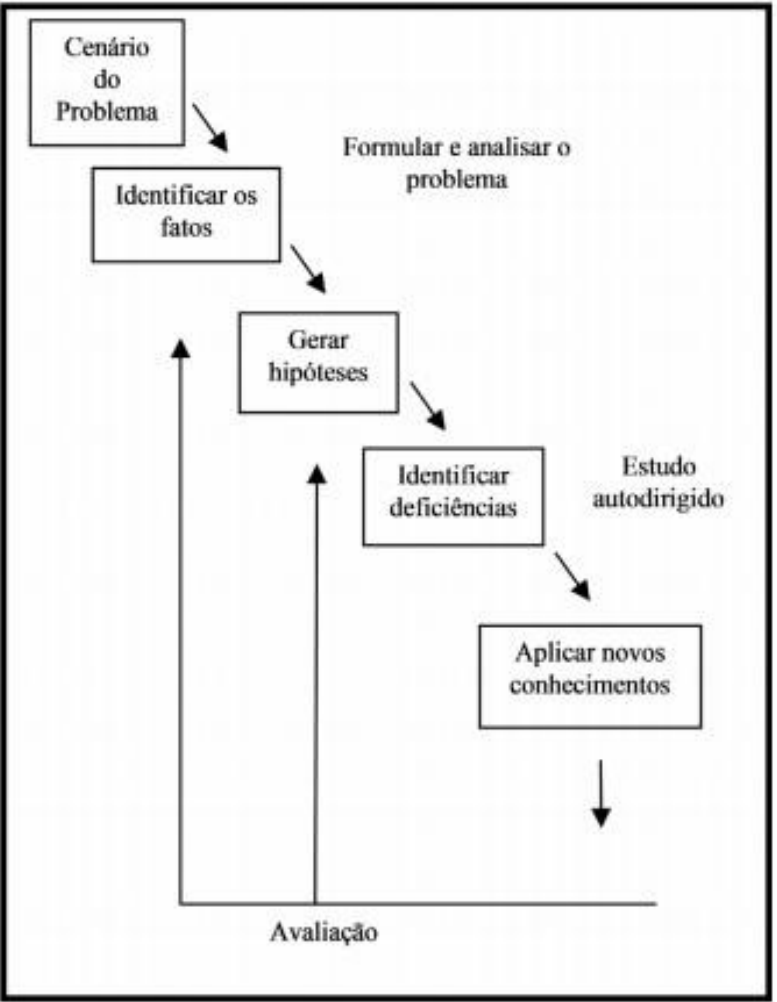

Figura 1 - O ciclo de aprendizagem na ABP (extraído de Lopes et al., 2011, p. 1276).

A apresentação do problema consiște na etapa em que se utilizam textos instigadores como meio para gerar discussão em sala. Essa etapa leva em torno de duas horas-aula, a fim de que a temática seja discutida de forma satisfatória.

Já a fase de elaboração de uma solução para o problema contempla quatro questões norteadoras, de acordo com Delisle citada por Lopes et al. (2001), conforme ilustrado no Quadro 1:

Quadro 1 - Estratégia para resolver o problema (adaptado de Delisle apud Lopes et al., 2001, p. 1278).

\begin{tabular}{|c|c|c|c|}
\hline $\begin{array}{c}\text { O que você sabe } \\
\text { sobre o assunto? }\end{array}$ & $\begin{array}{c}\text { Ideias para solucionar } \\
\text { o problema }\end{array}$ & $\begin{array}{c}\text { O que preciso saber } \\
\text { sobre o assunto? }\end{array}$ & Plano de ação \\
\hline
\end{tabular}


Listagem de todas as Valorização do informações sobre a questão levantada. conhecimento prévio dos estudantes.
Levantamento de

conhecimentos que precisam ser adquiridos para solucionar o problema.
- Onde buscar as informações?

- É necessário realizar análises? Quais?

- Analisar resultados.

Essa metodologia potencializa o desenvolvimento de uma atitude proativa na educação científica, maximizando a interação, a participação e o envolvimento dos estudantes no processo de aprendizagem. Trata-se de um trabalho abrangente relacionado ao cotidiano do acadêmico. Assim, os problemas surgem primeiro e, na medida em que os questionamentos são levantados, os conceitos e as competências vão sendo desenvolvidos, sendo as soluções um dos produtos desse processo.

$\mathrm{Na}$ área de ensino de Química, em particular, que possui uma quantidade elevada de conceitos abstratos aos estudantes, a aprendizagem baseada na resolução de problemas é capaz de aproximar o discente dos problemas reais que a sociedade precisa resolver ou está enfrentando. Dessa forma, é necessário buscar estratégias e/ou conhecimentos técnicos a fim de encontrar ou sugerir uma solução cabível à problemática exposta. De acordo com Batinga e Teixeira (2014, p. 10), alguns aspectos precisam ser levados em consideração: (i) delinear o tipo de problema que deverá ser trabalhado; (ii) deve estar intimamente ligado ao cotidiano; (iii) seja possível de ser resolvido, utilizando-se de uma estratégia relativamente simples e/ou adequada ao amadurecimento do aluno até então; e (iv) capaz de interligar: conceito, técnicas e atitudes na construção do conhecimento.

Segundo Campos e Nigro (1999), o processo de aprendizagem por problemas dentro do ensino de Química precisa ter, antes de tudo, uma abordagem investigativa, para que aproxime o discente da forma como o conhecimento científico é construído e tente afastá-lo do senso comum, que origina diversos problemas. A estratégia de trabalho consiste em elaborar de forma sequencial e cooperativa, a fim de envolver e comprometer o estudante com o assunto abordado, de modo que ele sinta a necessidade de buscar cada vez mais informações sobre o tema.

Para Grasselli e Colasurdo (2012, p. 7), alguns itens que estimulem o pensamento científico são de extrema importância para caracterizar uma ABP no contexto acadêmico: 
a. Limitação do problema: embora a abordagem seja ampla, é necessário limitar ou focar o problema, a fim de delimitar estratégias de resolução.

b. Formulação de hipóteses: a hipótese é um dos pilares da criação do pensamento científico, assim, hipóteses devem ser levantadas, antes que sejam definidas quais realmente merecem atenção e precisarão ser testadas, para obter respostas ao problema em questão.

c. Organização das informações: os dados (se houver) devem ser ordenados do mais para menos relevante, com base nas hipóteses levantadas.

d. Questionamento dos resultados obtidos: os resultados devem ser confrontados com os questionamentos levantados nas hipóteses, procurando olhar sob outros ângulos para verificar a coerência das respostas obtidas, ou ainda, avaliar a necessidade de reanalisar as hipóteses iniciais e, consequentemente, as estratégias adotadas.

Também com enfoque no ensino de Química, Batinga e Teixeira (2014) ainda enfatizam que o processo de aprendizagem por problemas, unido à inserção da metodologia científica, deve possuir: (i) uso de enunciados diretos, isto é, buscar textos que instiguem o interesse do aluno pela questão, no qual possa relacionar suas experiências com o conhecimento químico; (ii) o estudante deve entender com clareza o problema que está sendo colocado, o assunto químico envolvido; elaborar em grupo, possíveis estratégias de resolução, com coerência ao conhecimento químico, entendendo que as respostas nem sempre são óbvias e rápidas de serem resolvidas; (iii) verbalização e registro do que está sendo feito durante o processo, evitando a resolução sem reflexão; e (iv) análise dos resultados, sempre retomando as hipóteses levantadas, questionando se são relevantes e se podem ser confirmados de outras formas ou mesmo, se devem ser refeitas ou melhoradas.

Nessa abordagem, é importante destacar que não se pode negligenciar as dificuldades enfrentadas pelo professor, dentre elas estão: a elaboração do problema inicial, que seja ao mesmo tempo instigante e de fácil assimilação; dificuldade em envolver o aluno e mantê-lo focado na estratégia de resolução; dificuldade apresentada pelos estudantes em usar o raciocínio lógico; além de interpretar o enunciado, entender o que está sendo proposto e ainda, selecionar os conceitos teóricos que serão necessários para essa resolução. Vale destacar que o uso de uma nova metodologia não é garantia de 
sucesso na sua adoção em sala de aula; o conhecimento da técnica e a dedicação do docente são essenciais para o seu êxito.

As exigências emergentes das mudanças que temos observado no mundo do trabalho têm afetado diversos setores, principalmente aqueles ligados a Ciência e Tecnologia. Desta forma, os interessados por uma formação que atenda a demandas como a capacidade de resolver problemas têm procurado cursos de formação superior cujas grades curriculares ofereçam potencial para o desenvolvimento de habilidades e competências de alto nível (FINK, 2003).

O presente estudo visou avaliar a aprendizagem, mediante a aplicação da metodologia de Aprendizagem Baseada em Problemas, em aulas de Química Analítica de turmas de um curso Engenharia Química. Esta pesquisa foi apoiada financeiramente pela Finep e desenvolvida em um projeto de formação docente conduzido pelo Centro de Ensino e Aprendizagem (CrEAre), da PUCPR.

\section{METODOLOGIA}

Para a realização desse relato de experiência, tomou-se como universo amostral 5 turmas de $6^{\circ}$ período de um curso de Engenharia Química, que cursaram a disciplina de Química Analítica no $2^{\circ}$ semestre de 2017 e nos dois semestres de 2018, totalizando 133 estudantes.

Após algumas semanas do início do semestre, tendo já sido discutidos temas de estudos associados a equilíbrio químico em sistemas aquosos e, em aulas experimentais, os estudantes já tendo realizado algumas marchas analíticas de identificação de cátions e ânions por via úmida, a turma, dividida em times de trabalho, recebeu a descrição do cenário da situação-problema. O texto do material está apresentado a seguir: 
Cenário: Uma barragem que segregava lama tóxica de uma empresa de mineração rompeu-se, espalhando por milhares de quilômetros quadrados os dejetos químicos armazenados durante anos de funcionamento. Localizada na região sudeste do Brasil, o corrido configurou-se um desastre ambiental de proporções nunca vistas no país, contando com mortes de mais de uma dezena de pessoas, além de danos incalculáveis na fauna e na flora da região. Com este quadro instalado, a Analytics, uma empresa de consultoria pericial ambiental, foi contratada para levantar os índices de contaminação em vários pontos da região. Esta empresa trabalha com estações analíticas móveis e terceiriza o trabalho técnico, de modo que, para assumir o serviço de consultoria em questão, terá que contratar dez novos times de profissionais qualificados em análises químicas analíticas. As vagas serão oferecidas a engenheiros químicos, químicos e engenheiros ambientais. Após análises de currículos, os profissionais serão reunidos em equipes de 4 a 5 integrantes e haverá momentos de avaliação individual e do grupo. Supondo que seu time tenha se inscrito para disputar uma vaga desta empresa, segue o desafio da $1^{\text {a }}$ etapa classificatória:

O grupo receberá uma amostra de água de uma das regiões afetadas. Trata-se de uma região cujos impactos visíveis, caracterizados preliminarmente por ecologistas, indicam a possibilidade de contaminação por derivados ionizados de chumbo, mercúrio e prata. Aplicando algum método clássico de análise qualitativa de metais, o grupo deverá propor um método de identificação, aplicar e gerar um relatório detalhado, constando:

\section{Primeira parte:}

1.Lista dos materiais utilizados

2.Descrição do procedimento por texto e por fluxograma.

\section{Segunda parte:}

3.Explicação de cada etapa e justificativa dos reativos empregados, com base em fundamer teóricos de Química Analítica (reações químicas envolvidas, constantes de equilíbrio, fate explorados $-\mathrm{pH}$, temperatura, concentração).

4. Considerações finais e referências bibliográficas

(AUTORAS, 2017).

Foi disponibilizado pela professora um roteiro contendo as rubricas com os critérios de correção, como um protocolo a ser seguido na elaboração da apresentação (Quadro 2), de forma que os estudantes ficassem cientes dos detalhes que seriam julgados em cada etapa do trabalho.

Quadro 2 - Rubricas utilizadas na correção do relatório escrito (AUTORAS, 2017). 
ISSN: 2595- 4520

\begin{tabular}{|c|c|c|c|c|}
\hline $\begin{array}{l}\text { RUBRICAS } \\
\text { DAS } \\
\text { QUESTÕES }\end{array}$ & $100 \%$ dos pontos & $75 \%$ dos pontos & $\mathbf{5 0 \%}$ dos pontos & $25 \%$ dos pontos \\
\hline $\begin{array}{l}\text { 1. materiais e } \\
\text { reagentes } \\
\text { (peso: } 1,0)\end{array}$ & $\begin{array}{l}\text { Lista de reagentes } \\
\text { com todas as } \\
\text { concentrações das } \\
\text { soluções e } \\
\text { vidrarias para o } \\
\text { experimentos. } \\
\text { (cátions e ânions) }\end{array}$ & $\begin{array}{l}\text { Lista de reagentes com } \\
\text { todas as concentrações } \\
\text { das soluções e } \\
\text { vidrarias para o } \\
\text { experimentos. (apenas } \\
\text { para cátions OU } \\
\text { ânions) }\end{array}$ & $\begin{array}{l}\text { Lista de reagentes } \\
\text { (sem concentrações } \\
\text { das soluções) e } \\
\text { vidrarias dos } \\
\text { experimentos de } \\
\text { análise de cátions e de } \\
\text { ânions. }\end{array}$ & $\begin{array}{l}\text { Lista de reagentes } \\
\text { (sem concentrações } \\
\text { das soluções) e } \\
\text { vidrarias dos } \\
\text { experimentos de } \\
\text { análise apenas de } \\
\text { cátions ou apenas de } \\
\text { ânions. }\end{array}$ \\
\hline $\begin{array}{l}\text { 2. Procedimento } \\
\text { (peso 2,0) }\end{array}$ & $\begin{array}{l}\text { Relato completo } \\
\text { do experimento } \\
\text { COM fluxograma } \\
\text { dos experimentos } \\
\text { de cátions e } \\
\text { ânions. }\end{array}$ & $\begin{array}{c}\text { Relato completo do } \\
\text { experimento COM } \\
\text { fluxograma dos } \\
\text { experimentos } \\
\text { CONTENDO APENAS } \\
\text { cátions OU ânions. }\end{array}$ & $\begin{array}{l}\text { Relato completo do } \\
\text { experimento OU } \\
\text { fluxograma dos } \\
\text { experimentos de } \\
\text { análise de cátions E } \\
\text { de ânions. }\end{array}$ & $\begin{array}{l}\text { Relato completo do } \\
\text { experimento OU } \\
\text { fluxograma dos } \\
\text { experimentos de } \\
\text { análise apenas de } \\
\text { cátions ou apenas de } \\
\text { ânions. } \\
\end{array}$ \\
\hline $\begin{array}{l}\text { 3. Explicação de } \\
\text { cada etapa e } \\
\text { justificativa dos } \\
\text { reativos } \\
\text { empregados } \\
\text { (peso: } 5,0)\end{array}$ & $\begin{array}{c}\text { Todas as reações } \\
\text { químicas } \\
\text { envolvidas, } \\
\text { constantes de } \\
\text { equilíbrio de } \\
\text { formação de } \\
\text { precipitado (Kps), } \\
\text { ácidos fracos (Ka) } \\
\text { fatores explorados } \\
\text { - pH, temperatura, } \\
\text { concentração, } \\
\text { efeito do íon } \\
\text { comum - dos } \\
\text { experimentos de } \\
\text { análise de cátions. }\end{array}$ & $\begin{array}{c}\text { Maioria das reações } \\
\text { químicas envolvidas, } \\
\text { constantes de equilíbrio } \\
\text { de formação de } \\
\text { precipitado (Kps), de } \\
\text { formação de ácidos } \\
\text { fracos (Ka) ou de } \\
\text { formação de complexos } \\
\text { metálicos (Kcomplex); } \\
\text { fatores explorados - } \\
\text { pH, temperatura, } \\
\text { concentração, efeito do } \\
\text { íon comun - dos } \\
\text { experimentos de análise } \\
\text { de cátions. }\end{array}$ & $\begin{array}{l}\text { Apenas algumas das } \\
\text { reações químicas } \\
\text { envolvidas, constantes } \\
\text { de equilíbrio para } \\
\text { reações de formação } \\
\text { de precipitado (Kps), } \\
\text { de formação de ácidos } \\
\text { fracos (Ka) } \\
\text { fatores explorados - } \\
\text { pH, temperatura, } \\
\text { concentração, efeito } \\
\text { do íon comun - dos } \\
\text { experimentos de } \\
\text { análise de cátions. }\end{array}$ & $\begin{array}{l}\text { Apenas algumas das } \\
\text { reações químicas } \\
\text { envolvidas, SEM } \\
\text { constantes de } \\
\text { equilíbrio para } \\
\text { reações de formação } \\
\text { de precipitado (Kps), } \\
\text { de formação de ácidos } \\
\text { fracos (Ka) } \\
\text { fatores explorados - } \\
\text { pH, temperatura, } \\
\text { concentração, efeito } \\
\text { do íon comum - dos } \\
\text { experimentos de } \\
\text { análise de cátions. }\end{array}$ \\
\hline $\begin{array}{l}\text { 4. Considerações } \\
\text { finais } \\
\text { (peso: 1,5) }\end{array}$ & $\begin{array}{l}\text { Avaliação bem } \\
\text { fundamentada da } \\
\text { eficiência do } \\
\text { método } \\
\text { empregado, } \\
\text { diagnóstico do } \\
\text { problema } \\
\text { apresentado e } \\
\text { riscos em função } \\
\text { dos resultados } \\
\text { (elementos } \\
\text { encontrados). } \\
\end{array}$ & $\begin{array}{c}\text { Avaliação } \\
\text { razoavelmente } \\
\text { fundamentada da } \\
\text { eficiência do método } \\
\text { empregado em função } \\
\text { do problema a ser } \\
\text { resolvido; diagnóstico } \\
\text { do problema } \\
\text { apresentado e riscos em } \\
\text { função dos resultados } \\
\text { (elementos } \\
\text { encontrados). } \\
\end{array}$ & $\begin{array}{l}\text { Apenas avaliação da } \\
\text { eficiência do método } \\
\text { empregado em função } \\
\text { do problema a ser } \\
\text { resolvido. }\end{array}$ & $\begin{array}{l}\text { Apenas diagnóstico } \\
\text { do problema } \\
\text { apresentado e riscos } \\
\text { em função dos } \\
\text { resultados (elementos } \\
\text { encontrados). }\end{array}$ \\
\hline $\begin{array}{c}\text { 5. Referências } \\
\text { bibliográficas } \\
\text { (peso: } 0,5)\end{array}$ & $\begin{array}{l}\text { Todas as } \\
\text { referências } \\
\text { segundo normas da } \\
\text { ABNT. }\end{array}$ & $\begin{array}{l}\text { A maioria das } \\
\text { referências segundo } \\
\text { normas da ABNT. }\end{array}$ & $\begin{array}{l}\text { Apenas algumas } \\
\text { referências segundo } \\
\text { normas da ABNT. }\end{array}$ & \\
\hline
\end{tabular}

Toda a pesquisa foi desenvolvida extraclasse e as equipes, compostas por três a quatro estudantes, deveriam cumprir algumas etapas pré-determinadas com prazos estipulados, que consistiram basicamente em: envio de uma proposta de trabalho, 
contendo todo material necessário, reagentes, vidrarias, equipamentos que seriam utilizados e a metodologia proposta. A execução do projeto ocorreu durante a aula prática, com duração máxima de noventa minutos, sendo que foi oferecida às equipes que não atingiram seus objetivos uma nova oportunidade prevista no calendário da disciplina.

$\mathrm{Na}$ realização da parte experimental, foi solicitado aos estudantes que filmassem todo o processo, para que depois, extraclasse, montassem um vídeo com duração de 5 a 10 minutos. Esse vídeo, cujas orientações de elaboração foram disponibilizadas previamente, também compôs os materiais avaliados na resolução da situaçãoproblema.

A entrega do relatório completo ainda contou com a obrigatoriedade do preenchimento de uma ficha de avaliação por pares (peer assessment), onde cada aluno avalia a participação e envolvimento dos demais colegas da sua equipe atribuindo-lhe uma nota que varia de 0 a 10, sendo 0 (zero) que não houve participação nenhuma e 10(dez) total envolvimento deste na elaboração do trabalho como um todo. Tal atividade possui a finalidade de oportunizar aos integrantes da equipe dar e receber feedback dos pares para que possa refletir sobre sua atuação no grupo além de incentivá-los a serem co-responsáveis pelo processo avaliativo além de melhorar seu engajamento e a valorizar o processo de construção do trabalho e não apenas o relatório final.

\section{RESULTADOS E DISCUSSÃO}

Por tratar-se de uma metodologia inovadora, proativa e que exige comprometimento, responsabilidade e empenho por parte dos estudantes, houve uma certa resistência inicial por parte de alguns alunos que não haviam adquirido, até então, uma postura de protagonista de seu processo de aprendizagem. Em ocasiões em que se percebeu a expectativa de uma abordagem tutelada de ensino, foi necessário retomar a fala da importância da formação de profissionais autônomos, reflexivos e criativos no mercado de trabalho atual. Nestes momentos fez-se necessário, que o professor retomasse a relevância da atividade para o sucesso da equipe, retomando o enfoque e nível de engajamento que um trabalho desta natureza precisa, para ser realizado com êxito. 
No decorrer dos três semestres nos quais a metodologia foi aplicada, houve uma percepção na melhora de rendimento acadêmico dos estudantes, devido a qualidade do trabalho entregue pelas equipes, revelando que, apesar do formato original da proposta ter se mantido, a intencionalidade pedagógica e a sensibilização para o trabalho foram crescentes e como sugere Moura et al (2018) o ensino sendo praticado de uma forma mais crítica, faz com que os estudantes se tornem profissionais e cidadãos críticos e atuantes na sociedade, pois uma abordagem contextualizada, faz com que o conteúdo tenha sentido para o estudante e seja percebida sua aplicação prática e o discente se veja no papel de um profissional que pode fazer a diferença na sociedade.

Uma outra observação, ilustrada na Figura 2, mostra os índices gerais de aprovação dos estudantes no $2^{\circ}$ semestre de 2017 e nos dois semestres de 2018 , quando se implantou novas estratégias de ensino, todos baseados em Metodologias Ativas.

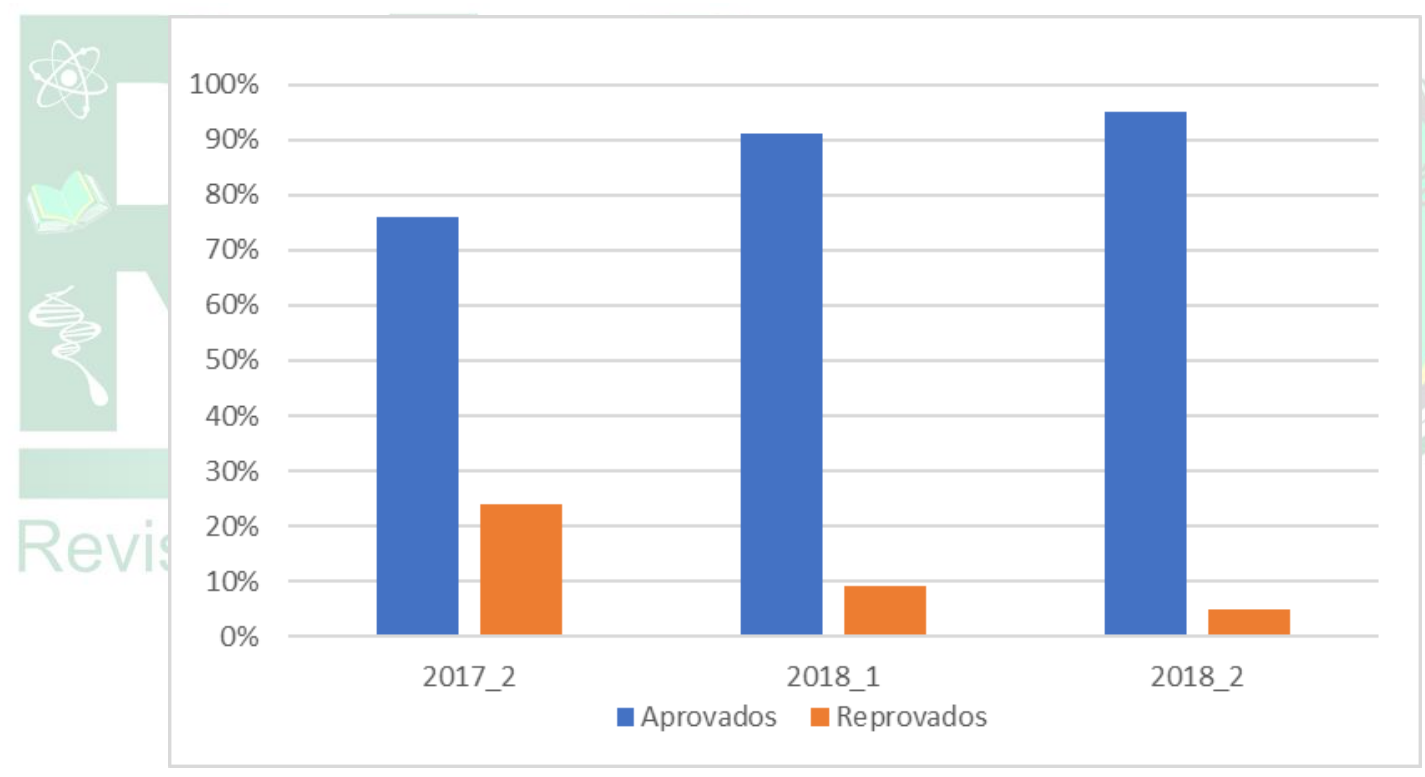

Figura 2 - Índices de aprovação na disciplina de Química Analítica, em 2017 ( $2^{\circ}$ semestre) e $2018\left(1^{\circ}\right.$ e $2^{\circ}$ semestre $)$.

Observa-se um perceptivo aumento nas taxas de aprovação, corroborando com a percepção do quanto o envolvimento e engajamento, dos estudantes, nas atividades propostas, faz a diferença não só para elevar seu conceito na disciplina mas contribuir para sua efetiva aprendizagem, tornando-o mais reflexivo e autônomo, aprofundando sua experiência e engajamento no processo de aprendizagem, além de desenvolver sua habilidade em lidar com conflitos e perceber a relevância do processo e não apenas seu conceito final. 
Ao se avaliar a estratégia utilizada pela percepção dos estudantes ao término de cada semestre, por meio de questionários aplicados via Google forms ${ }^{\circledR}$, mesmo os estudantes mais relutantes ao método assumiram que a qualidade da aprendizagem foi qualitativamente superior em relação ao desenvolvimento intelectual experimentado em situações de ensino meramente transmissivo e que o engajamento foi muito maior durante sua execução.

A realização de marchas analíticas repetitivas e não reflexivas terem dado lugar a uma abordagem de contexto real também foi um ganho de tempo e qualidade de discussão dos resultados experimentais. A pesquisa prévia associada ao registro do experimento com a utilização de ferramentas de vídeo qualificou a apresentação do material produzido de maneira cooperativa. Estas constatações vão ao encontro das conclusões de Araújo (2016), que defende que associações bem planejadas e aplicadas entre teoria e prática no ensino de Química Analítica promovem situações que potencializam a aprendizagem em níveis de maior aprofundamento que os obtidos com metodologias tradicionais.

\section{CONSIDERAÇÕES FINAIS}

A adoção de um método diferente para as aulas, em que o estudante precisa ser ativo na construção do seu conhecimento, apresentou um impacto positivo na grande maioria dos alunos, pois a proposta não apenas oportunizou aos estudantes desenvolver sua própria aula prática, mas também em aplicar em uma situação-problema dentro de um contexto real, para tanto, exigiu da equipe uma postura de protagonista no processo de aquisição de conhecimento e no desenvolvimento de habilidades, como autonomia e pensamento crítico, que pode ser confirmado também, nas percepções dos estudantes nas respostas dadas nos questionários realizados ao final da disciplina.

Ainda há aspectos a serem aprimorados, tratando-se da área da educação um processo em contínua evolução, mas o fundamental é iniciar uma nova maneira de ensinar e uma nova forma de aprender, envolvendo muito mais os estudantes e descentralizando o conhecimento da imagem do professor. $\mathrm{O}$ uso da $\mathrm{ABP}$ como abordagem central para desenvolver habilidades cognitivas de alto nível é um caminho muito promissor para aqueles educadores que estão constantemente preocupados com uma formação integral de seus estudantes. 


\section{REFERÊNCIAS}

ARAÚJO, R. B.;AMAMOTO, Y.;ABREU, D. G. Avaliação da aprendizagem em atividade experimental de Química: instrumentos de avaliação na disciplina de Química Analítica. Berlin (Alemanha): Novas Edições Acadêmicas,2016.

BATINGA, V. T. S.;TEIXEIRA, F. M. A Abordagem de resolução de problemas por uma professora de Química: análise de um problema sobre a combustão do álcool envolvendo o conteúdo de estequiometria. Revista Brasileira de Ensino de Ciência e Tecnologia, v. 7, n. 1, p. 24-52, 2014. Disponível em: $<$ https://periodicos.utfpr.edu.br/rbect/article/view/1357/1220>. Acesso em: fev. 2019.

CAMPOS, M. C. C.; NIGRO, R. G. Didática de ciências: o ensino-aprendizagem como investigação. São Paulo: FTD, 1999.

FINK, L. D. Creating significant learning experiences:an integrated approach to designingcollege courses. San Francisco: Jossey-Bass, 2003.

GIL PÉREZ, D.; FURIÓ MÁS, C.;VALDÉS, P.;SALINAS, J.;MARTÍNEZTORREGROSA, J.;GUISASOLA, J.;GONZÁLEZ, E.; DUMAS-CARRÉ, A.;GOFFARD, M.;PESSOA DE CARVALHO, A. M.Tiene sentido seguir distinguiendo entre aprendizaje de conceptos, resolución de problemas de lapiz y papel y realización de practicas de laboratório?Enseñanza de las ciencias: revista de investigación y experiencias didácticas, v. 17, n. 2, p. 311-320, 1999. Disponível em: <https://www.raco.cat/index.php/Ensenanza/article/view/21581/21415>. Acesso em: fev. 2019.

GRASSELLI, M. C.;COLASURDO. Reacciones químicas: un enfoque integrado.Educación Química, México, v. 12, n. 4, p. 233-239, out. 2001. Disponível em:<http://revistas.unam.mx/index.php/req/article/view/66332/58243>. Acesso em: mar. 2019.

LOPES, R.M.;SILVA FILHO, M. V.;MARSDEN, M.;ALVES, N. G. Aprendizagem baseada em problemas: uma experiência no ensino de Química toxicológica. Química Nova, São Paulo, v. 34, n. 7, p. 1275-1280, 2011. Disponível em:<http://quimicanova.sbq.org.br/imagebank/pdf/Vol34No7_1275_28-ED10646.pdf>. Acesso em: mar. 2019.

MOURA, F. M. T.; SOUZA, R.F.; SÁ CARNEIRO, C.C.B. O Ensino de Química Contextualizado: As Vozes Discentes. Revista Insignare Scientia. Vol 1, n.3, Set/Dez. 2018. Disponível em: <https://periodicos.uffs.edu.br/index.php/RIS/article/view/8849/7098>. Acesso em: 01.04.2020.

POZO, J. I. Aprendizes e mestres: a nova cultura da aprendizagem. Porto Alegre: Artmed, 2002. 
ROSA, M. F.;SILVA, P. S.;GALVAN, F. B. Ciência Forense no Ensino de Química por Meio da Experimentação. Revista Química Nova na Escola, Vol 37, No 1, p. 35-43. São Paulo, 2015. Disponível em:<http://qnesc.sbq.org.br/online/prelo/RSA-40-13.pdf〉. Acesso em: mar. 2019.

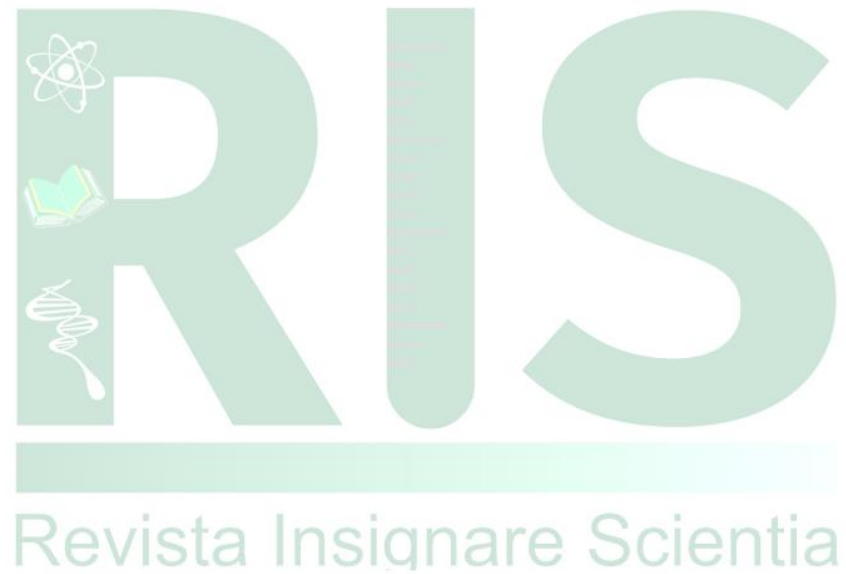

